\title{
Intramolecular Cyclizations and Ring-Cleavage Reactions of Five-Membered Heteroarylnitrenes and their Precursors
}

\author{
Maria Funicello, ${ }^{a}$ Piero Spagnolo*,a and Paolo Zanirato*,b \\ a Dipartimento di Chimica, Università della Basilicata, Via N. Sauro 85, I-85100 Potenza, Italy and bipartimento di \\ Chimica Organica 'A. Mangini', Università di Bologna, Viale Risorgimento 4, 1-40136 Bologna, Italy
}

\begin{abstract}
Funicello, M., Spagnolo, P. and Zanirato, P., 1993. Intramolecular Cyclizations and Ring-Cleavage Reactions of Five-Membered Heteroarylnitrenes and their Precursors. - Acta Chem. Scand. 47: 231-243.

The formal generation of nitrenes at the $\alpha$-position of aromatic five-membered heterocyclic systems almost invariably results in the opening of the original heteroaromatic ring leading to the formation of a nitrilic hetero-1,3-diene product. Similarly, the formal generation of nitrenes at the $\beta$-position of certain azole systems gives rise to ring-cleavage resulting in the formation of two fragments containing two or three of the original ring atoms. However, it is in general by no means clear whether the above ring-cleavage reactions actually proceed from initially formed nitrenes or directly from their precursors. On the other hand, normal arylnitrene behaviour can be exhibited by nitrenes generated at the $\beta$-position of the thiophene, furan, and selenophene rings. In fact, these latter $\beta$-nitrenes, in the presence of a suitable ortho-substituent, appear to undergo intramolecular cyclizations in a fashion comparable to that of the similarly substituted phenylnitrenes.

In this article we survey and discuss the known instances of the title reactions of five-membered heteroarylnitrenes and their precursors which have appeared in the literature up to the end of 1990.
\end{abstract}

Dedicated to Professor Salo Gronowitz on the occasion of his 65 th birthday.

Arylnitrenes are neutral reactive nitrogen intermediates possessing a sextet of electrons in their outer shell. Deactivation to the triplet can occur by intersystem crossing (ISC) as shown in $\mathbf{1} \rightarrow \mathbf{2}$.

$$
\begin{aligned}
& \mathrm{Ar}-\ddot{\mathrm{N}}: \stackrel{\text { ISC }}{\longrightarrow} \mathrm{Ar}-\ddot{\mathrm{N}} \text {. } \\
& 12
\end{aligned}
$$

Singlet arylnitrenes normally behave as weak electrophilic species, whereas triplet arylnitrenes exhibit reactions characteristic of diradical species.

By far the most widely used method for producing arylnitrenes is thermolysis or photolysis of aryl azides which readily lose two of the three nitrogen atoms as $\mathrm{N}_{2}$ [eqn. (1) ]. ${ }^{1}$ The pyrolysis temperatures required for

$$
\mathrm{Ar}-\mathrm{N}_{3} \stackrel{\Delta \text { or } h \mathrm{v}}{\longrightarrow} \mathrm{Ar}-\ddot{\mathrm{N}}:+\mathrm{N}_{2}
$$

simple phenyl azides are usually in the range $100-180^{\circ} \mathrm{C}$ but structural features may lower the temperature considerably. This occurs especially when $\alpha, \beta$-unsaturated substituents, such as $\operatorname{ArN}=\mathrm{N}-, \mathrm{O}=\mathrm{N}(\mathrm{O})-, \mathrm{O}=\mathrm{C}(\mathrm{R})$-, and $\mathrm{RN}=\mathrm{C}(\mathrm{R})$ - groups, are present in the ortho-position.

* To whom correspondence should be addressed.
In such cases loss of nitrogen generally results in smooth cyclization to fused azoles [eqn. (2)] through a mechanism involving some kind of neighbouring-group assistance, thus by-passing the occurrence of a discrete nitrene. $^{1}$

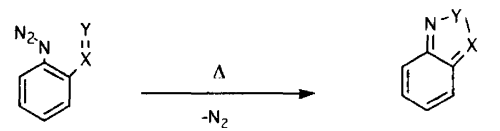

Deoxygenation of aromatic nitro and nitroso compounds with various tervalent phosphorus compounds, especially triethyl phosphite, is the next most widely used method for generating arylnitrenes [eqn. (3)]. Nitro

$$
\begin{aligned}
& \mathrm{ArNO}_{2}+(\mathrm{EtO})_{3} \mathrm{P} \longrightarrow \mathrm{ArNO}+(\mathrm{EtO})_{3} \mathrm{PO} \\
& \mathrm{Ar} \ddot{\mathrm{N}}:+(\mathrm{EtO})_{3} \mathrm{PO} \stackrel{\left.(\mathrm{EtO})_{3} \mathrm{P}\right\rfloor}{ }
\end{aligned}
$$

compounds react less readily than nitroso compounds; temperatures above $100^{\circ} \mathrm{C}$ are usually required. Nevertheless nitro compounds are more widely used, because they are normally much more readily available. In general, the same sorts of product are formed as from aryl azides but it is not certain whether discrete nitrenes or nitrene-like (nitrenoid) intermediates are actually produced. ${ }^{1}$ 
Other sources of arylnitrenes are known but these are usually not practicable because of the unavailability of starting material.

Over the last three decades an overwhelming amount of work has been dedicated to the generation of arylnitrenes and the investigation of their chemical reactivity both from theoretical as well as synthetic points of view. The versatile utility of arylnitrenes (and their progenitors) in organic synthesis, especially in heterocyclic synthesis, is now very well recognized. Considerable work has also been devoted to the study of the chemistry of sixmembered heteroarylnitrenes which in general has been found to be similar to that of the arylnitrene analogues. For relevant information about the attractive features of the chemistry of arylnitrenes and six-membered heteroaryl analogues the reader is referred to the numerous useful books and reviews which have recently been dedicated to this matter. ${ }^{1-5 a}$

By comparison much less work has been performed to investigate the chemical behaviour of 'nitrenes' attached to five-membered heteroarene systems. A limiting factor for a parallel study of the chemical reactivity of these heteroarylnitrenes has been the fact that the preparation of their azido precursors has often encountered serious difficulties. Indeed, aryl azides are most generally prepared by diazotization of the corresponding aniline followed by addition of sodium azide. This method, which has found application in the synthesis of azides derived from several types of azole (particularly imidazoles, ${ }^{6}$ thiazoles, ${ }^{7}$ pyrazoles, ${ }^{8}$ triazoles ${ }^{9}$ and isoxazoles ${ }^{10}$ ), has a limited scope in five-membered heteroaromatic systems since especially amines derived from rings containing one heteroatom (i.e., thiophenes, furans, pyrroles, etc.) are unstable compounds (unless electron-withdrawing substituents are present) and commonly give difficulties in diazotization.

Nucleophilic displacement of a halo group (or other suitable leaving group) by azide ion is an alternative (or complementary) method, but this is, however, only practicable provided that the aromatic ring is sufficiently activated. The few known azido-furans ${ }^{11-13}$ and -selenophenes ${ }^{11}$ have been prepared by this reaction. 3-Azido-2formylthiophene and a few azido(nitro)thiophenes have also been prepared by this method from corresponding bromothiophenes. ${ }^{11,12 b, 14,15}$ This method is obviously unsuited to the preparation of the parent azides or those carrying electron-releasing groups. Recently the parent 2- and 3-azidothiophenes (and -benzo $[b]$ thiophenes) as well as azidothiophenes having alkyl ${ }^{16}$ or aryl groups ${ }^{17}$ have been shown to be accessible by 'azido group transfer' reaction of corresponding lithium derivatives with tosyl azide.

However, possible extension of this reaction to the synthesis of azides derived from other aromatic heterocyclic systems is virtually unknown, but very recently 2-azidobenzo $[b]$ furan and 2-azido-1-methylindole have been prepared by a similar process. ${ }^{18}$

The limitations of the available methodology is consequently reflected in the fact that the number of the reported azides in the aromatic five-membered heterocyclic series is still relatively restricted. In general, systematic studies aiming to shed light on the chemical reactivity of the various possible nitrenes which can be derived from five-membered heteroaromatic systems have not been accomplished. Nevertheless, reported studies have uncovered the fact that the chemical behaviour of a five-membered heteroarylnitrene may largely depend upon the structural features and especially the position of the heterocyclic ring to which it is attached. In fact, a peculiar reactivity is associated with nitrenes formally generated at the $\alpha$-position of five-membered ring heteroarenes in that these 'nitrenes', largely irrespective of the nature of the adjacent ring, show a general tendency to suffer ring-opening of the type shown in Scheme $1 .^{5 \mathrm{~b}}$

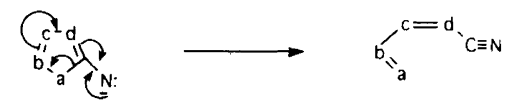

Scheme 1

Ring-opening reactions are normally not observed with arylnitrenes, but a number of examples have been encountered in the thermal rearrangements of 2-azido-pyridine and -quinoline 1-oxides and related compounds. ${ }^{19,20}$ On the other hand, 'nitrenes' generated at the $\beta$-position of the thiophene, furan, and selenophene rings appear to show a chemical reactivity not dissimilar from that of arylnitrenes, but 'those' produced at the $\beta$-position of certain azole ring systems normally undergo ringcleavage fragmentation in the manner shown in general in Scheme 2.

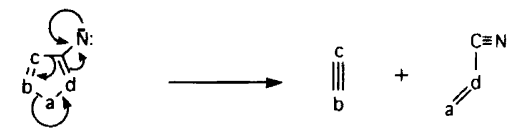

Scheme 2.

In this article we are concerned with the instances of ring-cleavage reactions of five-membered heteroarylnitrenes and their precursors which have appeared in the literature up to the end of 1990 . Moreover, we shall also discuss relevant instances of successful (and unsuccessful) intramolecular cyclization reactions which have been encountered with these nitrenes (and their precursors) in the presence of certain ortho-substituents. Since ring-cleavage fragmentations along with certain intramolecular cyclizations are by far the most widely investigated reactions of 'nitrenes' derived from fivemembered heteroarenes we shall provide an extensive perspective of the uncovered features of their chemistry.

\section{Intramolecular cyclization reactions of five-membered heteroarylnitrenes and their precursors}

There are numerous reports of 3-azido-thiophenes and -benzo $[b]$ thiophenes bearing an adjacent aryl or 
$\alpha, \beta$-unsaturated group [such as $\mathrm{RCH}=\mathrm{CH}-, \mathrm{RN}=\mathrm{CH}-$, or $\left.\mathrm{O}=\mathrm{N}(\mathrm{O})_{-}\right]$which, on thermolysis or photolysis, lead smoothly to the formation of fused azoles by intramolecular 1,5-cyclization in a fashion strictly comparable to that encountered with similarly substituted aryl azides [eqn. (2)]. In general, analogous results (when available) are reported for deoxygenations of corresponding 3-nitrothiophenes and -benzo $[b]$ thiophenes. 2-Azidobiphenyls are well known to afford carbazoles on thermolysis or photolysis through 1,5-electrocyclization of singlet nitrene intermediates. ${ }^{1-5}$ It is probable that a singlet nitrene mechanism is similarly involved in the formation of the benzothienoindole $4(56 \%)$ from thermolysis of 3-azido-2-phenylbenzo $[b]$ thiophene 3 , as observed by Iddon and Suschitzky in 1972 [eqn. (4)]. ${ }^{21}$

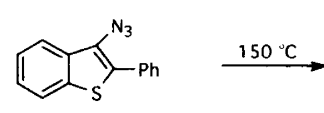

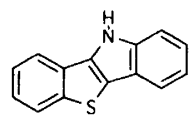

4
In the same work a number of 2-aryl-3-nitrobenzo [ $b]$ thiophenes were also shown to afford fused indoles in moderate yields on reductive cyclization with triethyl phosphite. More recently, 3-azido-2,2'-bithienyl 5 and 3-azido-2,3'-bithienyl 6 have been shown cleanly to undergo reaction of the same type when thermolysed in boiling chlorobenzene [eqns. (5) and (6)]. ${ }^{22}$ By con-
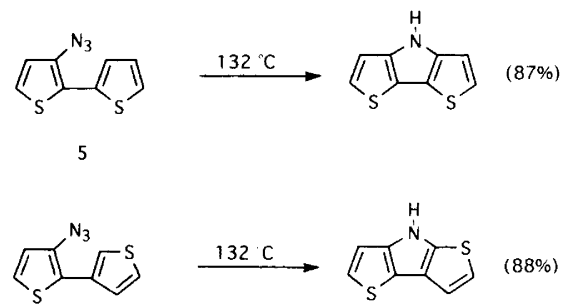

$(88 \%)$

6

trast, under comparable conditions the isomeric orthoazidobithienyls 7 and 8 led only to polymeric materials. The failure of azides 7 and 8 to cyclize to dithienopyrroles is presumably ascribable to the fact that concerted 1,5-electrocyclization is not a feasible process for the corresponding nitrenes. ${ }^{22}$
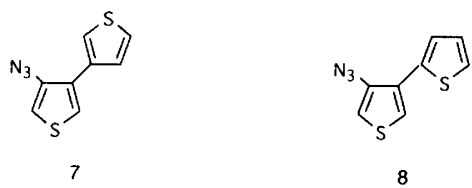

Singlet nitrenes derived from ortho-azido- or orthonitro-styrenes insert at the $\beta$-carbon to form indoles. ${ }^{1-5}$ Analogous cyclizations of thienyl and benzo $[b]$ thienyl $\beta$-'nitrenes' into an adjacent vinyl moiety have been encountered in several instances. Upon deoxygenation with boiling triethyl phosphite (E)-1-aryl-2-(3-nitro- 2-benzo[ $b]$ thienyl)ethylenes 9 furnish 2-arylbenzothieno$[3,2-b]$ pyrroles 10 in fairly good yields [eqn. (7)]. ${ }^{23}$

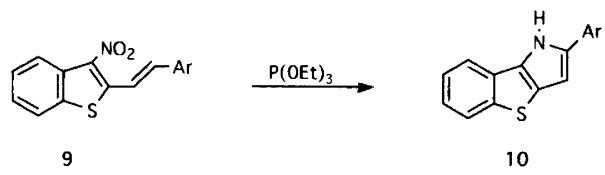

Analogous reductive cyclizations are undergone by corresponding nitrothiophenes 11 [eqn. (8)]. ${ }^{24,25}$ The

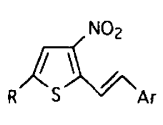

11
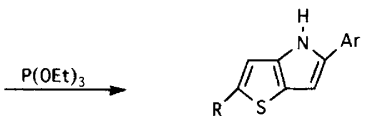

$\mathrm{R}=\mathrm{H}, \mathrm{COOMe}$ first instances of reactions of this type with $\beta$-thienylnitrenes thermally generated from azides were reported by Gronowitz and his co-workers in $1976 .^{26}$ The 3-azido2-vinylthiophene $12(\mathrm{R}=\mathrm{H})$, prepared by aldol condensation of 3-azido-2-formylthiophene with acetone, was in fact shown to afford the thienopyrrole $13(\mathrm{R}=\mathrm{H})$ in $90 \%$ yield upon thermal decomposition in boiling xylene [eqn. (9)].

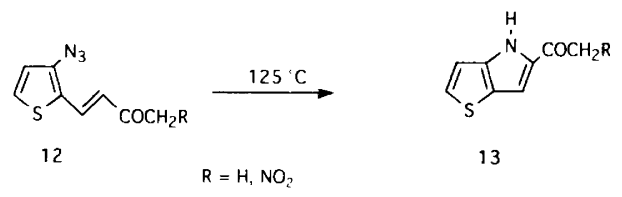

The nitro derivative $12\left(\mathrm{R}=\mathrm{NO}_{2}\right)$ behaved in a comparable fashion. Analogous thermal cyclizations were subsequently observed by Guilard et $a .^{27}$ with the $\beta$-azido-substituted 1,2-dithienylethylenes $14 \quad(\mathrm{Th}=2$ or 3-thienyl) which furnished the corresponding thienopyrroles $\mathbf{1 5}$ in good yield [eqn. (10)]. However,
S $\|_{T h}^{N_{3}}$

14

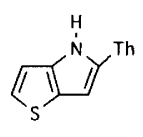

in contrast with the azides 14 (and by analogy with the two ortho-azidobithienyls 7 and 8 ), the isomeric azidoethylenes 16 ( $\mathrm{Th}=2$ - or 3-thienyl) failed to cyclize, giving only moderate yields of the triplet-nitrene derived products 17 [eqn. (11)].<smiles>Nc1cscc1/C=C/[InH2]</smiles>

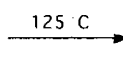

16<smiles>Nc1cscc1/C=C/[InH2]</smiles>

17
An interesting case arises when the thermally or photochemically generated 3-thienylnitrene bears a $\beta, \beta$ disubstituted vinyl moiety in the adjacent 2-position. In such cases the initial cyclized $2 \mathrm{H}$-thienopyrrole 18 under- 
goes isomerization to the eventual $1 H$-thienopyrrole 19 by successive [1,5]-sigmatropic shifts of one of its 2-substituents and hydrogen (Scheme 3). ${ }^{28,29}$ Rees and Moody

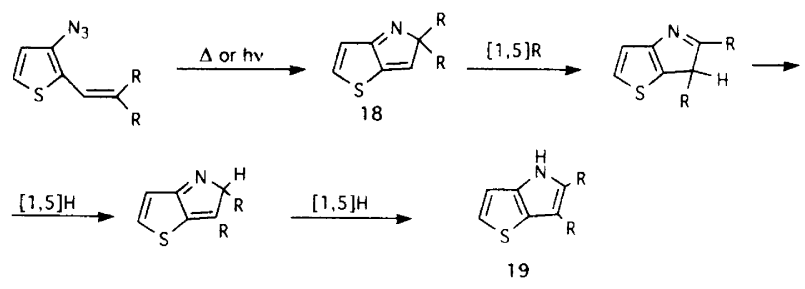

Scheme 3

were thus led to investigate the relative migratory aptitudes of a range of various groups by performing product studies of the photodecomposition of a number of 3-azidothiophenes having a suitable $\mathrm{RR}^{\prime} \mathrm{C}=\mathrm{CH}-$ substituent in the 2-position. ${ }^{30}$ In a related work the same authors discovered that in boiling toluene 3-azido-2-( $\beta$-thiovinyl)thiophenes 20 lead to fused 2-azathiabenzenes 21 rather than to cyclized pyrroles [eqn. (12)]. ${ }^{31}$ The singlet nitrenes derived from the azides 20 would therefore prefer to attack the vinylic sulfur $\beta$-substituent rater than the vinylic $\beta$-carbon.

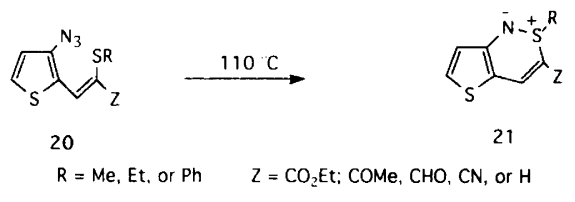

Benzothieno anils 22, obtained by condensation of 3-azido-2-formylbenzo [ $b$ ] thiophene with anilines, undergo clean cyclizations to fused pyrazoles 23 on thermal decomposition [eqn. (13)]. ${ }^{32}$

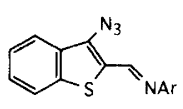

22
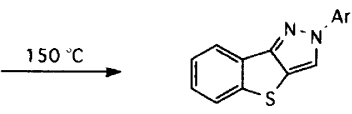

23
Since kinetic data have not been measured for these decomposition reactions, it is not clear whether discrete nitrenes or their azido precursors are implicated in the cyclization process. However, at least in the light of the kinetic evidence obtained from related decompositions of imines of ortho-azidobenzaldehyde, the actual intervention of nitrenes seems to be unlikely. The nitrobenzothieno (and -thieno) anil analogues of the azido anils 22 also afford fused pyrazoles on deoxygenation, but in lower yields. ${ }^{32,33}$

The 2-nitro-substituted 3-azidothiophenes 24 have been shown to furnish equilibrated mixtures of the thienofurazan oxides 25 and 26 on mild thermolysis [eqn. (14)]. ${ }^{14,15}$ Kinetic and thermodynamic data seem to rule out the possible intervention of nitrenes in these conversions, an electrocyclic mechanism involving concerted ring-closure and loss of nitrogen being preferable. ${ }^{14}$

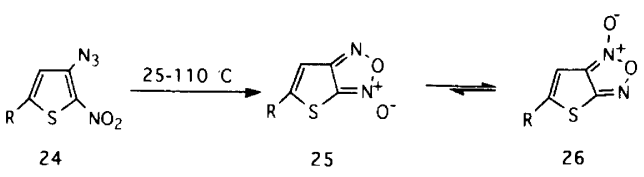

$\mathrm{R}=\mathrm{H}, \mathrm{CO}_{2} \mathrm{Me}$

Some additional instances of successful intramolecular cyclization reactions of the above type have been reported in the furan, thiophene and selenophene series by Gronowitz and co-workers. In 1975 Gronowitz prepared the ortho-azidoaldehydes $26(\mathrm{X}=\mathrm{O}, \mathrm{S}, \mathrm{Se})^{11}$ and studied their thermal decomposition. These azides underwent cyclization to the fused isoxazoles $27(X=O, S, S e)$ to varying extents [eqn. (15)]. ${ }^{34}$ The mechanism of these reactions was not investigated, since the authors were essentially concerned with their synthetic aspects. On the basis of general evidence for related thermal decompositions of phenyl azides bearing an ortho-carbonyl group ${ }^{2,3}$ it is possible that the above reactions occurred through concerted ring-closure and nitrogen extrusion.

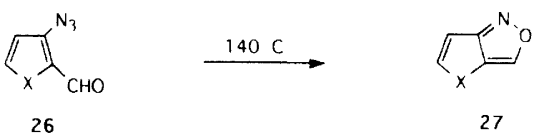

In a related study the anils $28(\mathrm{X}=\mathrm{O}, \mathrm{S}, \mathrm{Se})$, prepared from the corresponding azides 26 by reaction with aniline, were found to lead, on heating, to the cyclized pyrazoles $29(\mathrm{X}=\mathrm{O}, \mathrm{S}, \mathrm{Se})$ in fairly good yields [eqn. (16)]. ${ }^{35}$

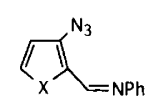

28

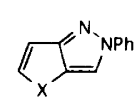

29
Moreover, the 3-azido-2-vinyl-furans $12 \quad(\mathrm{~S}=\mathrm{O}$; $\left.\mathrm{R}=\mathrm{H}, \mathrm{NO}_{2}\right)$ and -selenophenes $12\left(\mathrm{~S}=\mathrm{Se} ; \mathrm{R}=\mathrm{H}, \mathrm{NO}_{2}\right)$ have been shown cleanly to undergo thermal cyclization to the corresponding furopyrroles $13(\mathrm{~S}=\mathrm{O}$; $\left.\mathrm{R}=\mathrm{H}, \mathrm{NO}_{2}\right)$ and selenopyrroles $13\left(\mathrm{~S}=\mathrm{Se} ; \mathrm{R}=\mathrm{H}, \mathrm{NO}_{2}\right)$ in a fashion similar to their thiophene analogues 12 [eqn. (9)]. ${ }^{26}$ However, the $2-(\beta$-thienylthio $)$ vinyl-substituted 3-azidofuran $\mathbf{3 0}$ affords only the cyclic sulfimide 31 on thermal decomposition [eqn. (17)], as generally occurs with the similarly substituted 3-azidothiophenes 20. $^{31}$

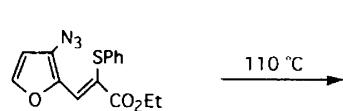

30

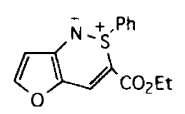

31
In contrast with the general pattern followed in the thiophene, benzo $[b]$ thiophene, furan, and selenophene series, the generation of 'nitrenes' at the $\beta$-position of various azole systems, in the presence of an adjacent $\alpha, \beta$-unsaturated group, failed to result in intramolecular cyclization and led instead to the cleavage of the hetero- 
aromatic ring. The known instances, although limited, will be discussed in the following section. Reported attempts to perform related intramolecular cyclizations with ortho-substituted $\alpha$-heteroarylnitrenes are less numerous; a large majority of these having met with total failure as a consequence of the marked tendency of the $\alpha$-'nitrenes' to undergo ring-opening.

No evidence for intramolecular cyclization to indole has been provided by 2-nitro-3-phenylbenzo[b]thiophene on deoxygenation, ${ }^{21}$ in stark contrast with the successful occurrence of the benzothieno[3,2-b]indole 4 from the isomeric 3-nitro-2-phenylbenzo $[b]$ thiophene or the corresponding azide 3 [cf. eqn. (4)]. ${ }^{21}$ The observed failure of 2-nitro-3-phenylbenzo $[b]$ thiophene to cyclize was ascribed by Iddon and Suschitzky to a peri-interaction between $\mathrm{H}-4$ and $\mathrm{H}-2^{\prime}$ of the phenyl ring which would prevent the required coplanarity for nitrene cyclization. However, the nature of the possible nitrenederived products remained unknown, since intractable material was essentially produced. In the light of subsequent studies, an alternative explanation might be that the intermediate $\alpha$-benzo $[b]$ thienylnitrene (or its precursor) failed to cyclize because of its strong propensity to suffer ring-opening. Careful re-investigation of the above deoxygenation reaction as well as a comparative study of the thermal decomposition reaction of (hitherto unknown) 2-azido-3-phenylbenzo [b] thiophene is desirable.

2-Azido-3,3'-bithienyl 32 and 2-azido-2',3-bithienyl 33 behave quite differently from the isomeric 3-azido-substituted bithienyls 5-8. They are thermally labile compounds which smoothly extrude molecular nitrogen at room temperature without evidence of formation of cyclization products. ${ }^{22}$ The fragmentation of the orthoazidobithienyl 32 leads mainly to two meta-dithiine isomers eventually resulting from ring-opening of the azide 32 or corresponding nitrene (see Section 3), whereas the decomposition of the azide $\mathbf{3 3}$ gives rise to intractable nitrile-containing materials.

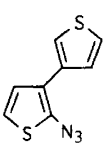

32

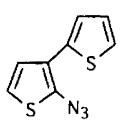

33
Thermolysis of the anil 34, available by condensation of 2-azido-3-formylbenzo[ $b]$ thiophene with aniline, results in a poor yield $(7 \%)$ of the cyclized benzothieno[2,3-c]pyrazole 35 [eqn. (18)], in sharp contrast with the smooth benzothieno[3,2-c]pyrazole production from pyrolysis of the 3-azido-substituted benzothienoanils 22 [eqn. (13)]. In such cases the main product $(60 \%)$ is the cyanoanil 36 [eqn. (18)], ascribable to sequential ring-opening/ring-closure of the thiophene moiety (see Section 3). ${ }^{32}$

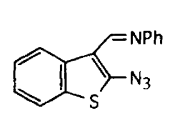

34

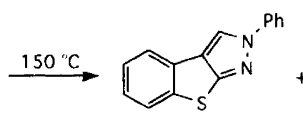

35

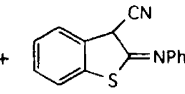

36
Deoxygenation of the anils derived from 3-formyl2-nitrobenzo $[b]$ thiophene appears to lead to comparable results. ${ }^{32}$ In a similar fashion, the thienoanil 37 gives no corresponding thienopyrazole, but instead undergoes a remarkable transformation of the thiophene ring into a pyrrole 38 through a related ring-opening/ring-closure reaction [eqn. (19)]..$^{33}$ On the other hand, the 3-vinylsubstituted 2-nitro-thiophenes (and -benzo $[b]$ thiophenes) 39 have been reported to cyclize to thieno (or benzo $[b]$ thieno)pyrroles $\mathbf{4 0}$ in fairly good yields on deoxygenation with boiling triethyl phosphite, with no mention of any ring fragmentation products [eqn. (20)]. ${ }^{23,25}$

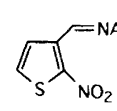

37<smiles>[3H]/C=C/c1c([N+](=O)[O-])sc2ccccc12</smiles>

39

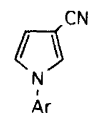

38

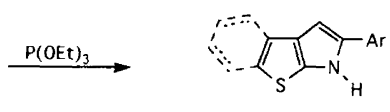

40
These findings are noteworthy since a vinyl moiety is not expected to be especially capable of intercepting an adjacent nitrene (or nitrenoid). An explanation of these intriguing findings awaits parallel studies of thermal and/or photochemical decompositions of the corresponding azido derivatives.

There is one instance of successful thermal cyclization of 2-azidothiophene onto an adjacent nitro substituent. At room temperature, 2-azido-5-methoxycarbonyl-3nitrothiophene $\mathbf{4 1}$ has in fact been shown to afford the same mixture $(97 \%)$ of the thienofurazan oxides 25 $(\mathrm{R}=\mathrm{COOMe})$ and $26(\mathrm{R}=\mathrm{COOMe})$ as that arising from fragmentation of the positional azido isomer 24 $(\mathrm{R}=\mathrm{COOMe})$ under the same conditions [cf. eqn. (14) $].{ }^{14}$ However, on the basis of kinetic evidence it is inferred that a nitrene mechanism is not involved in this reaction, but instead a concerted electrocyclic mechanism analogous to that occurring in the case of the isomeric azide $24(\mathrm{R}=\mathrm{COOMe}){ }^{14}$<smiles>COC(=O)c1cc([N+](=O)[O-])c(N)s1</smiles>

In the diazole and triazole series there are several examples of $\alpha$-azides and $\alpha$-nitroso compounds with adjacent aryl groups failing to cyclize to fused indoles on thermal and reductive generation of their nitrenes. Moreover, there are also some very recent examples of the failure of ortho-formyl substituted $\alpha$-azido-indoles and -pyrazoles to cyclize to fused isoxazoles on mild thermolysis. Since these reactions invariably resulted in ringopening fragmentations, they are discussed in Section 3. 


\section{Ring fragmentation reactions of five-membered $\beta$-heteroarylnitrenes and their precursors}

The known instances of ring-cleavage fragmentation of five-membered ' $\beta$-heteroarylnitrenes' are rather limited and invariably conform to the general pattern shown in Scheme 2 . They have commonly been encountered in the thermolysis of $\beta$-azides derived from pyrazoles, oxazoles and 1,2,3-triazoles which, in principle, can lead to nitrenes capable of extruding such a stable nitrogen-containing fragment $b \equiv c$ as a nitrile or molecular nitrogen. However, it is not clear whether the observed ring fragmentation reactions actually proceed through the intermediacy of discrete nitrenes or, instead, through concerted processes avoiding the generation of nitrenes in a distinct step.

The first instance of ring-cleavage fragmentation of a possible $\beta$-heteroarylnitrene was observed by Wright in 1968 in the course of his study of the deoxygenation of the readily available 3-methyl-4-nitroso-1,5-diphenylpyrazole $42 .{ }^{36}$ This study was initially undertaken with the expectation that the nitrene intermediate from 42 might undergo intramolecular cyclization to an indolo [2,3- $d]$ pyrazole. However, on deoxygenation with triethyl phosphite in boiling benzene, the nitrosopyrazole 42 did not lead to any of the expected indole compound, but instead suffered rupture of the ring, resulting in the formation of $\alpha$-phenyliminophenylacetonitrile $\mathbf{4 3}$ (70\%); acetonitrile, not detected, was assumed to have been the other product [eqn. (21)].

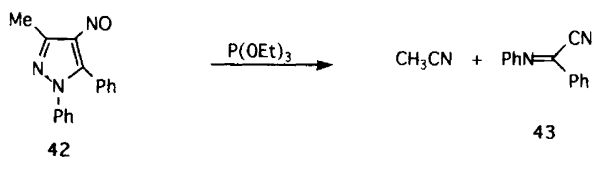

A systematic study of the ring fragmentations of 'nitrenes' thermally generated at the 4-position of pyrazoles by thermolysis of corresponding azidopyrazoles was reported by Smith and Dounchis in $1973 .^{8 a}$ These authors prepared a series of seven 4-azidopyrazoles 44 having methyl and/or phenyl substituents through the reaction of sodium azide with diazotized amines. All the prepared azidopyrazoles 44 were found to be unusually unstable for aryl azides, being decomposed (slowly) even at ambient temperature. Upon brief heating in boiling cyclohexane the azides 44 generally gave the nitrilic fragmentation products $\mathbf{4 5}$ in varying isolated yields in addition to simple nitriles (acetonitrile or benzonitrile) which were usually not isolated but detected spectroscopically [eqn. (22)]. In addition to the nitrilic fragmentation products, two of the azides, i.e., 4-azido-1,3,5-triphenyl$44\left(R^{1}=R^{2}=R^{3}=P h\right)$ and 4-azido-1-methyl-3,5-diphenylpyrazole $44\left(R^{1}=M e, R^{2}=R^{3}=P h\right)$, produced the

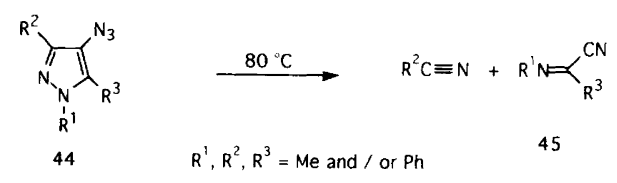

corresponding azopyrazole $46(\mathrm{R}=\mathrm{Ph}$ or $\mathrm{Me})$ to a significant extent.

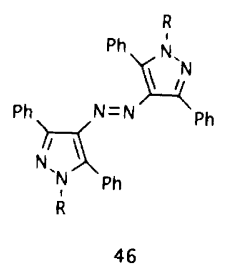

The formation of an azo-compound (formally a dimer of the triplet nitrene) was taken as diagnostic evidence that ring fragmentation of the azidopyrazole is not a concerted process, implying the initial occurrence of a nitrene intermediate. On this basis, the unusually easy decomposition of the azidopyrazoles 44 was explained as being the result of stabilization of the resulting singlet nitrenes, as shown in 47. However, the observed occasional

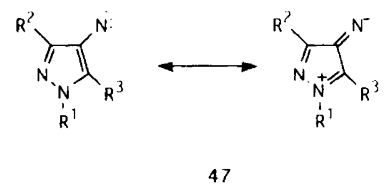

occurrence of the formally triplet nitrene-derived product 46 remains rather unclear. Possible intervention of a triplet nitrene in the formation of the azo-compound 46 was not supported by any concomitant formation of aminopyrazole; moreover, suitable attempts aiming to establish the role of nitrene in the formation of $\mathbf{4 6}$ were inconclusive. In the same work $^{8 \mathrm{a}}$ the 4-azido1,2,3-triazole 48 was similarly shown to undergo thermally induced ring fragmentation. In boiling toluene, in fact, the azide 48 was cleanly fragmented into two molecules of nitrogen and a molecule of the nitrile 43 [eqn. (23)].

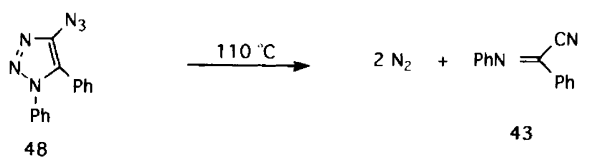

The cleavage of the isoxazole ring has been observed in a more recent study of the thermolysis of 4-azido5-vinylisoxazoles, which was initially undertaken in search of a synthetic route to the unknown pyrrolo$[2,3-d]$ isoxazole ring system. Thermolysis of the azide 49 in boiling decalin furnished the cinnamoyl cyanide $\mathbf{5 0}$ in $90 \%$ yield (and acetonitrile) and none of the desired pyrroloisoxazole [eqn. (24)]. A resonance contribution

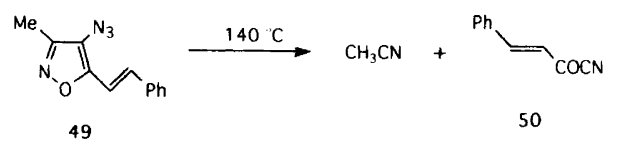

by the zwitterionic structure $\mathbf{5 1 A}$ to a postulated nitrene intermediate $\mathbf{5 1}$ was invoked to explain the observed 


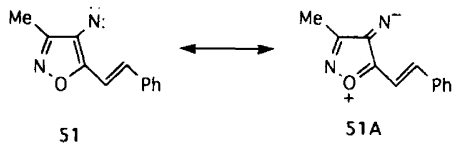

fragmentation of the azide 49. ${ }^{37}$ L'abbé and Godts have very recently ${ }^{10}$ carried out kinetic measurements on the thermal ring-cleavage fragmentation of the three alkylsubstituted 4-azidoisoxazoles $\mathbf{5 2 a - c}$ in order to shed possible light on the mechanism involved. Three mechanisms were taken into account by the authors: (i) a nitrene mechanism (Scheme 4, path a); (ii) a fully concerted mechanism (path b); and (iii) a reaction via an intermediate azirine (path c) similar to the decomposition of vinyl azides. Thermolyses of these azides, 52a-c, were cleanly first-order and independent of the solvent polarity. The values of activation energy determined in the three cases amounted to $25-26 \mathrm{kcal} \mathrm{mol}^{-1}$. These values, as compared with the $E_{\mathrm{a}}$ value $\left(38.5 \mathrm{kcal} \mathrm{mol}^{-1}\right)$ reported for the thermolysis of 4-methoxyphenyl azide to a fairly stabilized nitrene, were regarded as inconsistent with a nitrene mechanism. An azirine mechanism was considered to be inconsistent with the observed lack of strong steric retardation by the bulky tert-butyl R-substituent. Therefore, a concerted mechanism was believed to be most likely for the decomposition of the 4-azidoisoxazoles $52 .{ }^{10}$

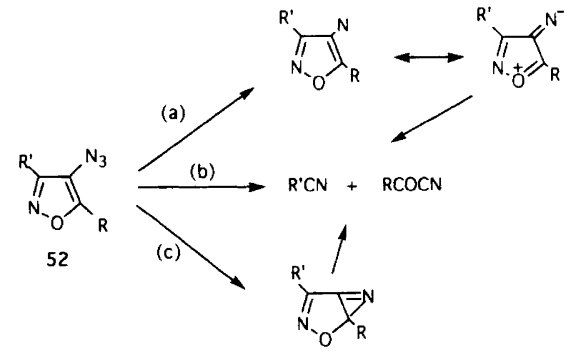

$a, R=M e, R^{\prime}=H ; b, R=C e_{3}, R^{\prime}=H ; C, R=R^{\prime}=M e$

Scheme 4.

A unique case of ring-cleavage of a 3-azido(or-nitreno)thiophene has been recently discovered. ${ }^{28}$ Condensation of 3-azido-2-formylthiophene with ethyl azidoacetate furnished the bis-azide 53; in boiling xylene this gave, besides ethyl thieno[3,2-c]pyridazine-3-carboxylate $54(26 \%)$, ethyl 5-cyanoisothiazole-3-carboxylate $55(27 \%)$ and acetylene $(21 \%)$ evidently arising by cleavage of the thiophene ring [eqn. (25)]. As shown in Scheme 5, the

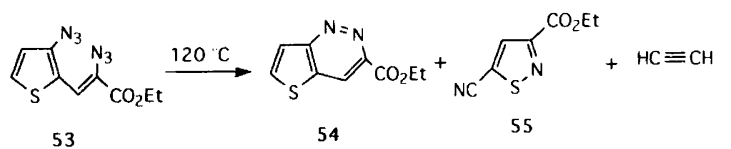

vinyl azide would play a crucial role in the ring-cleavage; the nitrene derived from it would co-ordinate with the thiophene sulfur to form the intermediate sulfimide $\mathbf{5 6}$, thereby weakening the ring. Loss of nitrogen could then occur with simultaneous (or subsequent) extrusion of acetylene and isothiazole (55) formation.

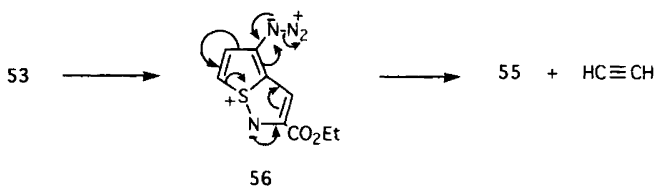

Scheme 5

Under identical thermolysis conditions the corresponding furan bis-azide $\mathbf{5 7}$ underwent no ring-cleavage reaction, but only led to the furopyridazine 58 (19\%) and tarry material [eqn. (26)]. ${ }^{28}$ This finding supports involvement of intermediate 56 in the fragmentation of 53. With the vinyl azide 57 the occurrence of the corresponding oximide $56(\mathrm{~S}=\mathrm{O})$ is expected to be less likely on the basis of the, presumably, less likely co-ordination of the intermediate nitrene to the furan oxygen. Interestingly, this work also uncovered two new examples of the rather uncommon process of intramolecular coupling of two nitrene equivalents.

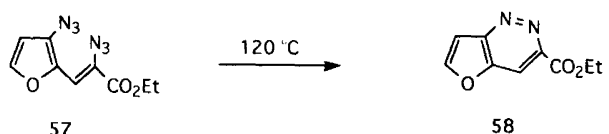

A peculiar type of ring fragmentation has been encountered with 3-azido-5-phenyl-1,2,4-oxadiazole 59 which, on flash vacuum pyrolysis, gave benzoyl cyanide in $70 \%$ yield. This transformation is explained (Scheme 6) by conversion of the azide 59 into its tetrazole tautomer 60 and thence to the pentaazafulvene 61 by $\mathrm{N}-\mathrm{O}$ bond cleavage. Subsequent loss of nitrogen from 61 by a $[2+2+2]$ cycloreversion would give benzoyl isocyanide which would rearrange to the product. ${ }^{38}$ Therefore, the thermal ring-cleavage fragmentation of the $\beta$-azidooxadiazole 59, which evidently avoids the intervention of the corresponding nitrene, results in a peculiar distribution $[4+1]$ of the ring atoms between the two fragments.

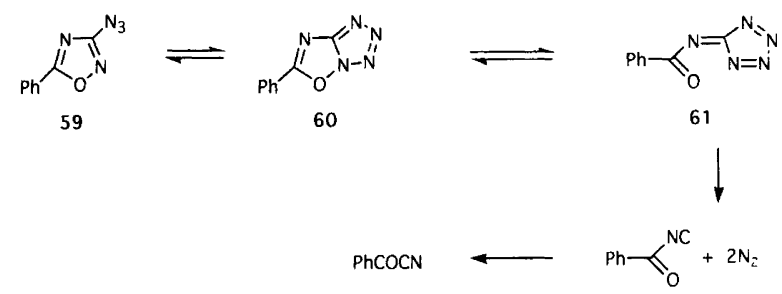

Scheme 6 .

\section{Ring-opening reactions of five-membered a-heteroarylnitrenes and their precursors}

As already mentioned in the Introduction, a ring-opening reaction of the type shown in Scheme 1 represents the (almost) exclusive process encountered whenever gene- 
ration of nitrenes has been attempted at the $\alpha$-position of aromatic five-membered ring heterocyclic systems. $\alpha$-Azides derived from, inter alia, thiophene, pyrrole, furan, pyrazole, and 1,2,3-triazole rings have generally been found to be thermally unstable compounds which, on decomposition, almost invariably give rise to the appropriate nitrilic ring-opened product. $\alpha$-Nitrothiophenes and -benzo $[b]$ thiophenes, as well as fused $\alpha$-nitroso-imidazoles and -pyrroles, on deoxygenation have also been found to undergo the same type of ringopening reaction, but a few exceptions are known as we have shown in Section 1. It is by no means certain whether such heterocyclic ring-opening reactions involve the intermediacy of discrete nitrenes and/or proceed directly from their precursors since the experimental evidence obtained to date is mostly inconclusive. Speculative suggestions in favour of nitrene intermediates have been put forward for most of the thermal azide fragmentations investigated, but one should try to seek a convincing explanation of the reasons why five-membered heteroaromatic $\alpha$-azides might decompose to initial nitrenes under usually very mild thermal conditions (ca. $25-50{ }^{\circ} \mathrm{C}$ ); conditions which are quite unusual for thermolyses of aryl azides to nitrenes and even for thermolyses of vinyl azides to azirines, which probably involve ring-formation with concerted nitrogen loss. ${ }^{39}$

The study of the thermolyses of 1,4-diaryl-5-azido1,2,3-triazoles, which was reported by Smith and coworkers in 1964, is of historical interest in that it provided the first documented evidence for ring-cleavage decompositions of five-membered heteroaryl azides. ${ }^{9 \mathrm{a}}$

The 1,4-diaryl-5-azido-1,2,3-triazoles 62, which in principle bear two sites for intramolecular cyclization, were prepared with the initial goal of finding out which factors might influence the possible preference for either thermal cyclization. However, the azides 62 were unexpectedly found to lose nitrogen at temperatures as low as $50^{\circ} \mathrm{C}$ and gave no cyclized products at all. Instead they gave rise, in high yield, to deep red, crystalline substances whose chemical and spectral properties were consistent with the open-chain triazene derivatives 64 [eqn. (27)]. These substances gave evidence of equilibration in solution with at least very low concentrations of the corresponding heterocyclic nitrenes 63. On this basis, the resonance-stabilized nitrenes 63 were believed to be likely intermediates in the observed fragmentation of the azides 62 [eqn. (27)]. However, the possible occurrence of an alternative, concerted process was not ruled out. ${ }^{9 a}$

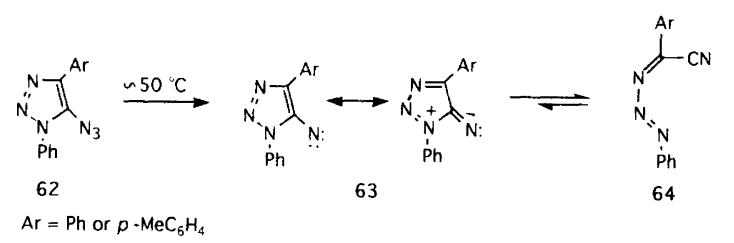

Very recently, further investigation of the thermal reactivity of the 4-substituted 5-azido-1-phenyl-1,2,3- triazoles 62 has revealed that an electron-withdrawing 4 -substituent can essentially suppress the ring-cleavage reaction in favour of isomerization to $\alpha$-diazotetrazoles 65. This process would involve initial ring-opening of the azidotriazole 62 to the diazo imine 66 followed by ring-closure to the eventual tetrazole product $\mathbf{6 5}$ [eqn. (28)]. ${ }^{9 \mathrm{c}, 40}$

A similar rearrangement has been encountered with 4-substituted 5-azido-1,2,3-thiadiazoles which, on thermolysis, undergo isomerization to $\alpha$-diazothiatriazoles rather than fragment into ring-opened products. ${ }^{41}$

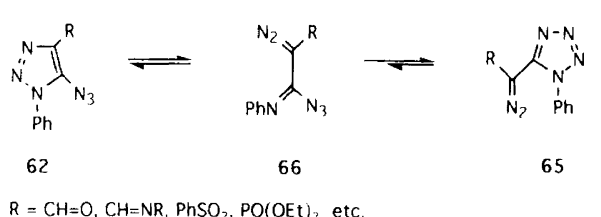

$\mathrm{R}=\mathrm{CH}=\mathrm{O}, \mathrm{CH}=\mathrm{NR}, \mathrm{PhSO}_{2}, \mathrm{PO}(\mathrm{OEt})_{2}$ etc.

The thermal behaviour of 5-azidopyrazoles bearing aryl and/or methyl substituents shows a close resemblance to that of the 1,2,3-triazolyl analogues. ${ }^{8 \mathrm{a}, \mathrm{b}}$ For instance, 5-azido-1,3,4-triphenylpyrazole 67 decomposes in solution slightly above room temperature to form the corresponding deep red, ring-opened product 68 in nearly quantitative yield [eqn. (29)]. This fragmentation product 68 remains quite stable in solution at temperatures below $100^{\circ} \mathrm{C}$, but at higher temperatures it is slowly converted into a 5,5'-azopyrazole dimer, formally ascribable to coupling of the pyrazolylnitrene 69 with which 68 would equilibrate to some extent [eqn. (29)].

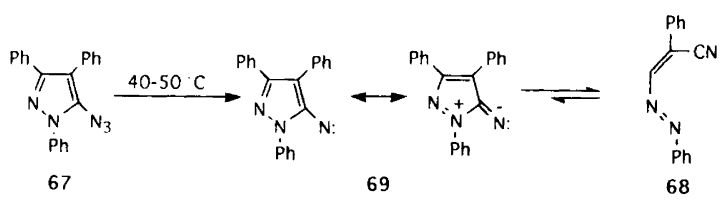

5-Azido-4-formyl-1-methylpyrazoles $\mathbf{7 0}$ are poorly isolable when they are prepared by the reaction of the corresponding 5-chloropyrazoles with an excess of sodium azide in dimethyl sulfoxide at $80^{\circ} \mathrm{C}$. Under these conditions the pyrazolyl $\alpha$-azides 70 undergo ringopening decomposition to give azoacrylonitrile intermediates from which the 1-azidomethyl-4-cyanopyrazoles 71 are ultimately formed through the mechanism outlined in Scheme 7.42a Anils derived from 5-azido-4-formyl1-phenylpyrazoles $70(\mathrm{Me}=\mathrm{Ph})$, upon thermolysis in

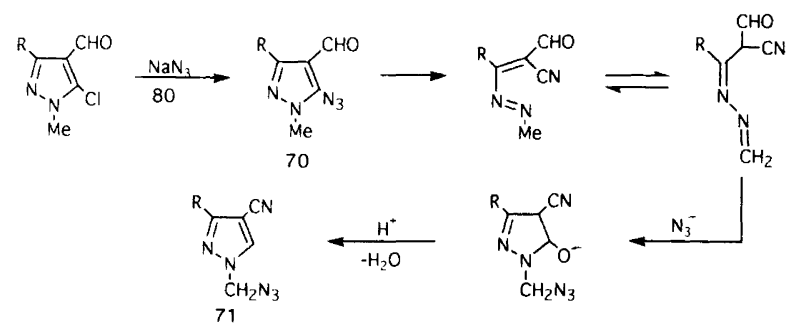

Scheme 7. 
refluxing chloroform, are cleanly converted into 5-arylamino-4-cyano-1-phenylpyrazoles through a related ringopening/ring-closure mechanism. ${ }^{42 b}$ Easy opening of the imidazolyl ring has been shown to occur in deoxygenations of 3-nitroso-2-phenylimidazo[1,2-a]pyridines 72 and -pyrimidines 73 with triethyl phosphite. In fact, these reactions generally lead to good yields of the corresponding ring-cleaved products 74 and 75 [eqn. (30)] and not at all to cyclized pyridino- and pyrimido-imidazoindoles, whose occurrence had been claimed at an earlier stage. ${ }^{43}$

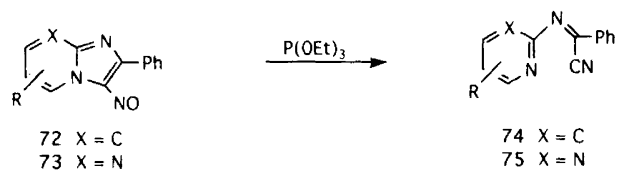

The slightly unstable 3-azido-2,1-benzisothiazoles 76 on fairly mild thermolysis or photolysis can suffer the cleavage of the isothiazole moiety to give the reactive thionitrosoarenes 77 which eventually lead to the sulfur diimides 78 by dimerization with loss of sulfur [eqn. (31)]. ${ }^{44}$ The transient thionitrosoarenes 77 can be usefully intercepted by performing decomposition of the azides 76 in the presence of suitable dienes capable of undergoing Diels-Alder reaction with the thionitroso function. ${ }^{44}$

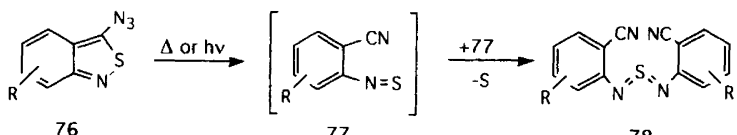

Photolysis of 5-substituted 2-azido-1,3,4-oxadiazoles 79 in methylene chloride results in virtually quantitative ring fragmentation. The initial cleavage probably follows the general pattern, but the ensuing product $\mathbf{8 0}$ would fragment spontaneously to give an acyl cyanide [eqn. (32)]. ${ }^{45}$ This reaction has been recommended for

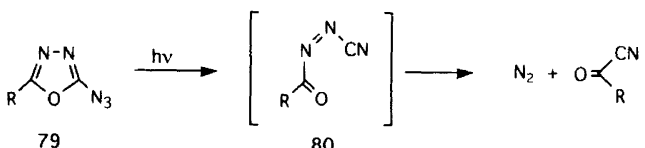

use in peptide synthesis since the azidooxadiazoles $\mathbf{7 9}$ are fairly well accessible from acylhydrazines and the acyl cyanides that are formed from them are readily converted into esters and amides by reaction with alcohols and amines. Nitrenes (or their precursors) attached at the $\alpha$-position of simple pyrroles do not appear to have been investigated, but cleavage of the pyrrole ring has been proved to occur in the oxidation of two aminopyrrolo$[1,2-c]$ pyrimidines as well as in the thermal decomposition of several 2-azidoindoles. On treatment with lead tetra-acetate, at room temperature, the 7-aminopyrrolopyrimidines 81 are converted into the corresponding pyrimidinylacrylonitriles $\mathbf{8 2}$ in fairly good yield [eqn. (33)]. ${ }^{46}$ The intermediacy of nitrenes derived from $\mathbf{8 1}$ has been postulated. There are in fact several reports of oxidation of heteroaromatic primary amines leading to products expected of nitrenes. However, the same nitriles 82 are also intriguingly produced on catalytic hydrogenation of the 7-nitroso derivatives $81\left(\mathrm{NH}_{2}=\mathrm{NO}\right){ }^{46}$<smiles></smiles>

81

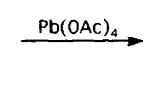

$\mathrm{R}=\mathrm{Me}$ or Ph

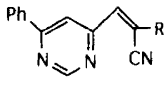

82
Reaction of the 1-substituted 2-chloro-3-formylindoles 83 with an excess of sodium azide in dimethyl sulfoxide takes place within ca. $5 \mathrm{~min}$ at $95-105^{\circ} \mathrm{C}$ to give the 5-azido-3-cyanoindoles 84 in moderate yields. ${ }^{47 a}$ The nitrilic products 84 are accounted for in terms of the mechanism depicted in Scheme 8, entailing ring-cleavage fragmentation of the initially formed 2-azido-3-formylindoles 85 incapable of surviving the thermal reaction conditions. The same reaction, when carried out at $20^{\circ} \mathrm{C}$ for ca. $20 \mathrm{~h}$, leads to the isolation of azidoindole 85 in almost quantitative yield. This finding strongly supports the intervention of azides $\mathbf{8 5}$ in the formation of nitriles 84 .

According to Becher and his co-workers, ${ }^{47 a}$ the relatively mild reaction conditions suggest a 'concerted process', probably involving nitrogen followed by ringopening via an ylide intermediate 86 without formation of a nitrene intermediate (Scheme 8). However, it might be argued that the ylide structure $\mathbf{8 6}$ should, in principle, be regarded as a zwitterionic nitrene form.

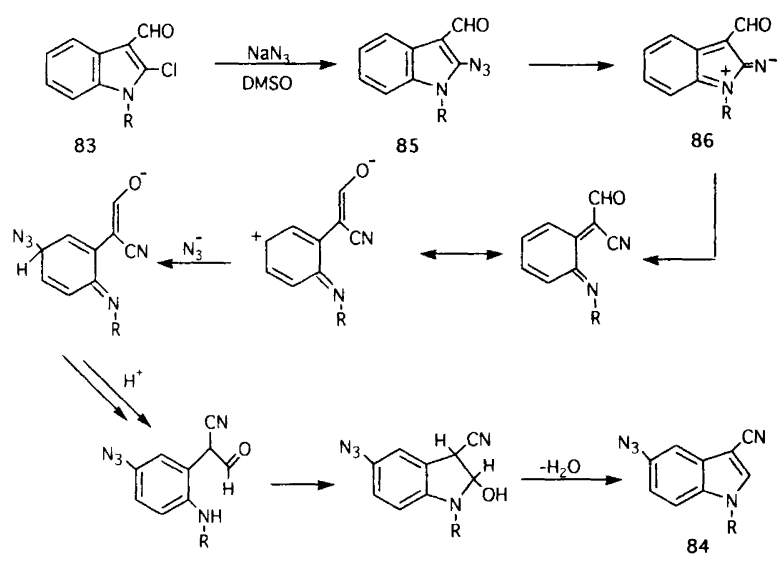

Scheme 8.

As with the 2-chloro-3-formylindoles 83, 1-alkylmethyl-2-chloro- (or 2-phenylsulfonyl)-3-phenylsulfonylindoles react with excess azide ion in $N, N$-dimethylformamide at $90^{\circ} \mathrm{C}$ to give thermally unstable 2-azido-3-phenylsulfonylindoles which eventually lead to 2-alkyl-3-cyanoindoles in varying yields through a related ring-opening/ring-closure reaction. ${ }^{47 \mathrm{~b}}$

2-Azido-1-methylindole 87, which we have recently prepared in $70 \%$ yield by 'azido group transfer' from tosyl 
azide to 2-lithiated 1-methylindole, on thermolysis in benzene at $25-60^{\circ} \mathrm{C}$ affords the diamine 88 in $60 \%$ yield. ${ }^{18}$ The diamine $\mathbf{8 8}$ is most likely formed by isomerization of the imine 89 initially produced by cyclodimerization of the ortho-quinoidal enimine 90 arising from the ringopening decomposition of the azide 87 [eqn. (34)]. When

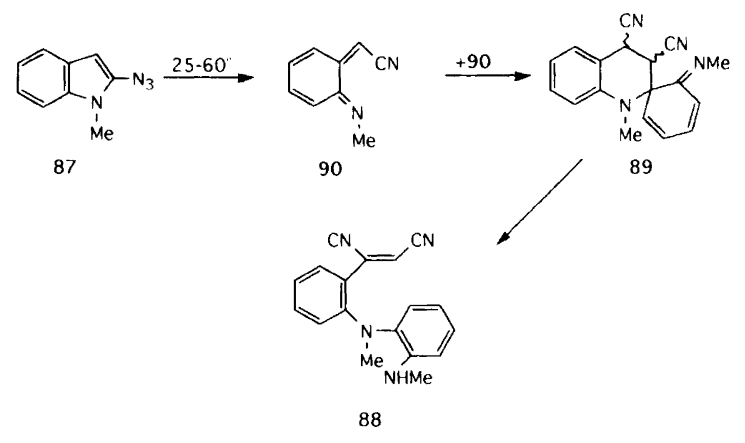

the azide $\mathbf{8 7}$ is allowed to decompose at room temperature in the presence of dimethyl fumarate (ca. 3 days) the cyclodimerization of the enimine 90 is essentially suppressed in favour of its cycloaddition reaction with the alkene leading to the tetrahydroquinoline 91 (43\%). In such a case, concomitant formation of the aziridine 92 $(25 \%)$ is observed (Scheme 9$)$. No diagnostic evidence for the possible involvement of a triazoline intermediate in the formation of aziridine 92 has been obtained. ${ }^{18}$

Analogous findings are furnished by the thermolysis of the azide 87 in methyl acrylate or acrylonitrile. We have explained our results by assuming that the nitrene derived from the azide 87 might be a common intermediate in the formation of the ring-opening and aziridine products (Scheme 9). However, further study is required to exclude the possibility that an elusive triazoline adduct rather than the postulated nitrene might actually be responsible for the observed occurrence of aziridine product.

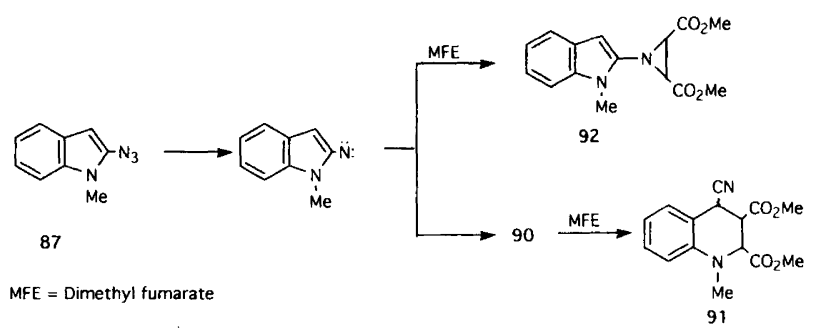

Scheme 9.

The most recent instances of azidoazoles conforming to the typical reactivity pattern of heteroaromatic $\alpha$-azides appear to be furnished by the 2-aryl-substituted 5-azido4-trifluoromethyl-1,3-oxazoles 93. These azidoazoles 93, which are obtained in moderate yields by treating the corresponding 5-fluoro derivatives with trimethylsilyl azide in tetrahydrofuran at $10-15^{\circ} \mathrm{C}$, are reported to be thermolabile and decompose even at room temperature to give the ring-cleaved acyl imines 94, a new attractive class of heterodiene, in high yields [eqn. (35) ]. ${ }^{48}$ However, it is worth noting that, curiously, the 1,3-thiazolyl analogues of the azides 93 are reported to be remarkably stable and show the normal reaction pattern of azides. ${ }^{48}$

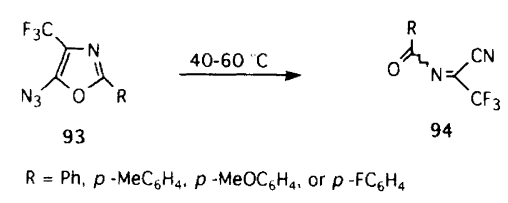

Very few 2-azidofurans have been reported. Those known invariably possess an electron-attracting substituent in the 5-position and are reportedly stable enough to be isolated, but cannot be stored at room temperature without suffering partial decomposition. ${ }^{12}$ In 1983 Newcombe and Norris clearly showed that the decomposition of these heterocyclic azides results in ring-cleavage by performing product and kinetic studies of the thermal fragmentation of the four 5-acyl-2-azidofurans 95a-d. ${ }^{13}$ These azides 95, which were prepared in moderate yield by reacting the appropriate 5-acyl-2-nitrofuran with sodium azide in dimethyl sulfoxide at $20^{\circ} \mathrm{C}$, on standing in solution or in the absence of solvent, at room temperature, were found to be converted into the corresponding dioxoalkenenitriles 96 within 5-15 days. The rather unstable ring-opened products 96 were fully characterized by spectroscopic techniques and also by formation of Diels-Alder adducts with 2,3-dimethylbuta-1,3-diene (DMBD) or 1,3-diphenylbenzo[c]furan (DBF) (Scheme 10).

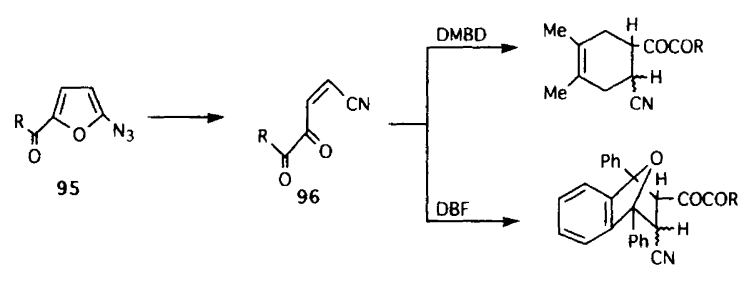

$a, R=H ; \quad b, R=M e ; c, R=P r^{\prime} ; d, R=B u^{\prime}$

Scheme 10.

Decomposition rates of the azides 95a-d were all firstorder over the temperature range examined $\left(20-50^{\circ} \mathrm{C}\right)$ and showed a slight, but definite increase with increasing bulkiness of the acyl R-group. The corresponding values of activation energy, which occurred in the range $24-26.5 \mathrm{kcal} \mathrm{mol}^{-1}$, were found to show a parallel decrease. On the assumption that the ring-opening reaction of the azides $95 \mathbf{a}-\mathbf{d}$ should proceed through the intermediacy of the corresponding nitrenes 97 , the authors

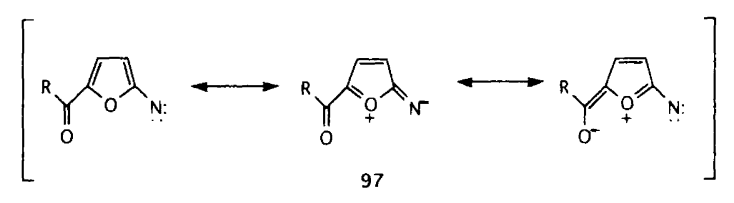

explained their kinetic observations in terms of relative stabilities of these nitrenes, which were essentially related 
to R-group steric effects. According to the authors, an increase in the size of $R$ would result in increased departure from coplanarity of the carbonyl group and thence in concomitant reduction of its unfavourable resonance conjugation with the furan ring.

The possibility that the thermal fragmentation of 2-azidofurans 95a-d might proceed through a non-nitrene mechanism was not put forward by Newcombe and Norris, though the observed $E_{\mathrm{a}}$ values were quite different from those encountered in thermolyses of aryl azides to nitrenes (generally $32-40 \mathrm{kcal} \mathrm{mol}^{-1}$ ). ${ }^{1}$

Very recently we reported the first instance of a 2-azidosubstituted benzo[b]furan. Indeed, we succeeded in preparing the parent 2-azidobenzo [ $b]$ furan 98 in ca. $70 \%$ yield by reaction of 2 -lithiated benzo $[b]$ furan with tosyl azide. ${ }^{18}$ It is noteworthy that this azide 98 can undergo ring-cleavage decomposition even when stored in the absence of solvent at $-20^{\circ} \mathrm{C}$. In fact, upon being stored in a freezer for several days, it largely converts into the azide 100 presumably by cycloaddition of its fragmentation product 99 to the furan ring of the unchanged azide [eqn. (36)]. The same product $\mathbf{1 0 0}$ can be isolated in $50 \%$ yield upon brief heating of 98 in benzene at $50-60^{\circ} \mathrm{C}^{18}$

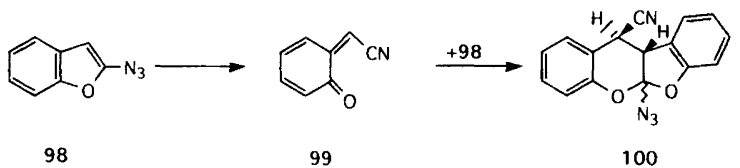

Kinetic evidence indicated that first-order ring-opening of azide 98 is ca. ten times faster than that of the related 2-azidobenzo $[b]$ thiophene, which was subsequently found probably to be a concerted process (vide infra). On this basis, our original assumption that the ring-opening of 2-azidobenzo[ $b]$ furan should proceed from an intermediate nitrene requires re-consideration. There are several reports of ring fragmentation of $\alpha$-nitrothiophenes (and -benzo $[b]$ thiophenes) upon reductive deoxygenation and of corresponding azides upon thermolysis. The first report appeared in 1973 by Iddon and Suschitzky from their study of the thermal decomposition of the azidoanil 34 as well as of the deoxygenations of a number of the related nitroanils 101 with triethyl phosphite. ${ }^{32}$ As mentioned in Section 1, pyrolysis of the azidoanil 34, carried out in refluxing bis-(2-methoxyethyl) ether, gave mainly the cyanoanil 36 [cf. eqn. (18)]. In a similar fashion, the nitroanils $101(\mathrm{R}=\mathrm{H}, o-\mathrm{Cl}, p-\mathrm{OMe}$ or $p$-NMe ${ }_{2}$ ), on being heated in boiling triethyl phosphite, gave, in each case, a rather poor yield of the corresponding pyrazole and a comparable (or major) amount of benzo $[b]$ thiophene-3-carbonitrile 102 (Scheme 11). The observed occurrence of the cyanoanil 36 and the nitrile 102 was explained in terms of successive ring-opening/ ring-closure of a common benzo $[b]$ thienoazirine intermediate 103 which was believed to be formed through an initially formed nitrene 104 (Scheme 11). ${ }^{32}$ However, evidence for the intermediacy of the azirine 103 and/or nitrene 104 was only circumstantial.

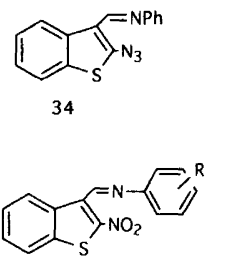

101

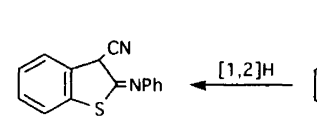

36
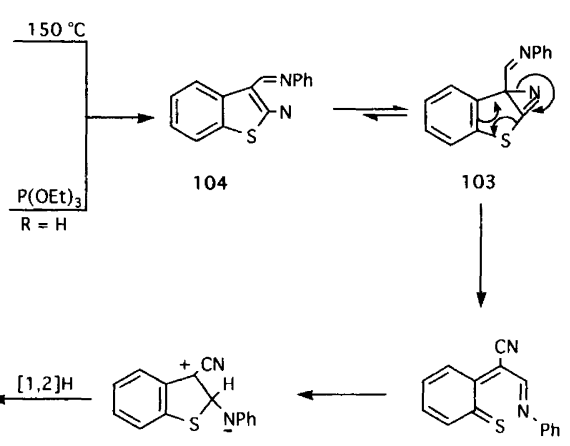

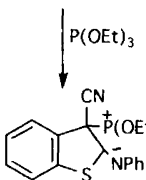

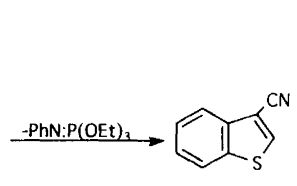

Scheme 11.
A similar mechanism, involving a sequential ringopening/ring-closure reaction of a thienoazirine intermediate, was proposed by Iddon and Suschitzky to explain the novel thiophene $\rightarrow$ pyrrole transformation which they subsequently encountered in the deoxygenation of the anils $37\left(\mathrm{Ar}=\mathrm{Ph}\right.$ or $\left.p-\mathrm{Me}_{2} \mathrm{NC}_{6} \mathrm{H}_{4}\right)$ derived from 3-formyl-2-nitrothiophene [cf. Section 1, eqn. (19)]. ${ }^{33}$

The ortho-azidobithienyl 32 undergoes spontaneous decomposition over several hours, to give an isomeric mixture of the meta-dithiine 105 and 106 in ca. $60 \%$ yield together with tarry material. Compounds 105 and 106 are conceivably ascribable to cyclodimerization of the ringcleaved enethione 107 initially produced [eqn. (37)]. ${ }^{22}$

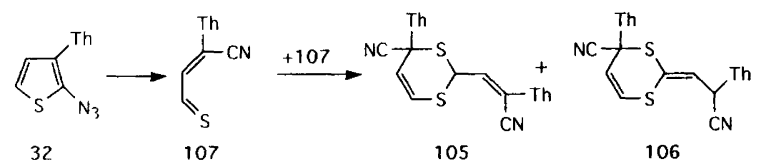

Ring-opening of the thiophene ring probably also occurs in the spontaneous decomposition of the isomeric ortho-azidobithienyl 33, but unfortunately this azide gives no identifiable products (cf. Section 1). ${ }^{22}$

2-Azidobenzo[ $b]$ thiophene 108 exhibits clean ringopening fragmentation upon thermolysis in benzene at $40-60^{\circ} \mathrm{C}$. In fact, we have recently observed that, under such thermal conditions, the azide 108 gives rise, in virtually quantitative yield, to an isomeric mixture of cis- and trans-dibenzo[bf $][1,5]$ dithiocine-6,12-dicarbonitrile 109 , which can be attributed to cyclodimerization of an ortho-quinoidal enethione intermediate [eqn. (38).$^{49}$

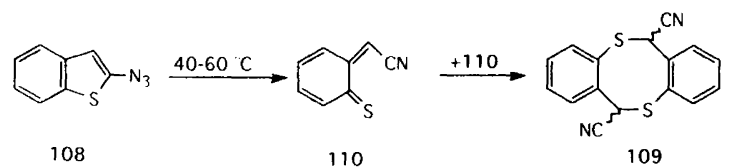


The intermediate 110 can be effectively trapped by Diels-Alder reaction with electron-poor and electron-rich alkenes. ${ }^{50}$ Indeed, the decomposition of azide 108 at $20-60^{\circ} \mathrm{C}$ in the presence of variously substituted alkenes resulted in the smooth formation of the appropriate 4-cyanothiochromans 111, which were, however, usually accompanied by the corresponding aziridines $\mathbf{1 1 2}$ to an extent largely increasing with decrease both in the reaction temperature and the nucleophilic character of the alkene employed (Scheme 12).

The aziridines $\mathbf{1 1 2}$ are not ascribable to additions of a singlet 2-nitrenobenzothiophene to the olefinic double bonds (which had been initially claimed), ${ }^{50}$ but most likely to fragmentations of reactive triazoline intermediates which would be formed in each case by bimolecular reaction of the azide 108 with the alkene present (Scheme 12). This fact is strongly supported by our observation $^{51}$ that, in the presence of $E$ - and $Z$-alkenes, the azide 108 can give rise to aziridine products in a nonstereospecific fashion. Additional support comes from our successful characterization of a triazoline intermediate in one case as well as from the finding that the rate of disappearance of 2-azidobenzo $[b]$ thiophene can be affected by the alkene present and its concentration. ${ }^{5}$

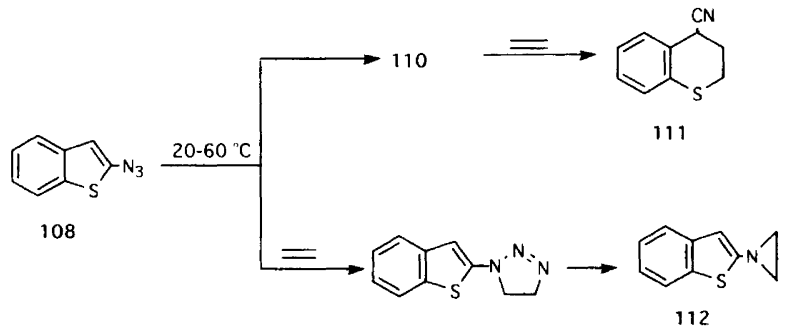

Scheme 12.

Thermal decomposition of the azide 108 in neat dialkylamines at $20-60^{\circ} \mathrm{C}$ results in high yields of the ortho-diamines 113, which are formed by addition of amine to the ring-cleavage product $\mathbf{1 1 0}$ followed by ringclosure of the resulting arenethiol (Scheme 13). ${ }^{52}$ No diagnostic evidence for the intermediacy of an azirine (or its nitrene tautomer) can be obtained under these circumstances (Scheme 13). By contrast, isomeric 3-azidobenzo $[b]$ thiophene may provide concrete evidence for the initial occurrence of an azirine intermediate when allowed to decompose in neat dialkylamines. ${ }^{52}$

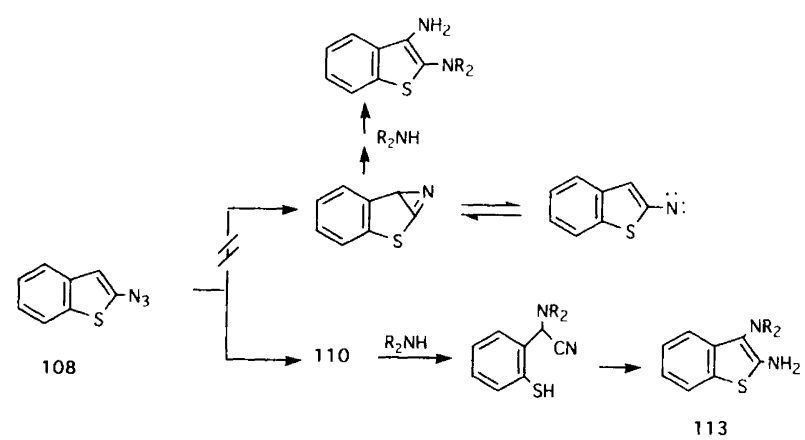

Scheme 13
The ring-opening reaction of 2-azidobenzo[b]thiophene 108 is first-order in ethylbenzene or benzene at $50-60^{\circ} \mathrm{C}$ and its activation energy is ca. $21 \mathrm{kcal} \mathrm{mol}^{-1}$, a value which seems much too low to be consistent with an azirine and/or nitrene mechanism. Therefore, chemical and kinetic evidence jointly point to a low-energy process, entailing concerted ring-opening and nitrogen loss. ${ }^{51,52}$

\section{Conclusions}

It is clear that the thermal decomposition of fivemembered heteroaryl $\alpha$-azides and the deoxygenation of corresponding nitro (or nitroso) compounds fail to give products expected of arylnitrenes (though a few curious exceptions are known), but result in the opening of the original heteroaromatic ring with formation of synthetically useful nitrilic heterodiene products.

Our understanding of the actual mechanism(s) involved in these ring-opening reactions is still limited, but the bulk of the available chemical and kinetic information would seem to suggest that the intervention of discrete nitrenes is unlikely. Similarly, the formal generation of nitrenes at the $\beta$-position of certain azole ring systems gives rise to ring-cleavage, resulting in the formation of two fragments containing two and three of the original ring-atoms, but the possible involvement of nitrene intermediates is still unclear. On the other hand, nitrenes generated at the $\beta$-position of five-membered heteroaromatic rings containing one heteroatom appear to follow the normal reaction pattern of arylnitrenes. Indeed, $\beta$-nitrenes derived from thiophenes, furans, and selenophenes, in the presence of a suitable substituent at the adjacent $\alpha$-position, usually afford intramolecular cyclization products in a fashion comparable to that of the similarly substituted phenylnitrenes.

Acknowledgments. The authors are very grateful to Dr. Brian Iddon (University of Salford) for reading the manuscript and providing valuable suggestions.

\section{References}

1. Smith, P. A. S. Aryl and Heteroaryl Azides and Nitrenes. In: Scriven, E. F. V., Ed., Azides and Nitrenes-Reactivity and Utility, Academic Press, New York 1984, Chap. 3.

2. Scriven, E. F. V. and Turnbull, K. Chem. Rev. 88 (1988) 297 and references therein

3. Dyall, L. K. In: Patai, S., Ed., The Chemistry of Halides, Pseudohalides and Azides, Wiley, Chichester 1983, Vol. 1, Chap. 7.

4. Suschitzky, H. Lect. Heterocycl. Chem. 5 (1980) 1.

5. (a) Iddon, B., Meth-Cohn, O., Scriven, E. F. V., Suschitzky, H. and Gallagher, P. T. Angew. Chem., Int. Ed. Engl. 18 (1979) 900; (b) Gilchrist, T. L. Adv. Heterocycl. Chem. 41 (1987) 42.

6. Rull, M. and Villarasa, J. J. Heterocycl. Chem. 14 (1977) 33.

7. Faure, R., Galy, J. P., Vincent, E. J. and Elguero, J. J. Heterocycl. Chem. 14 (1977) 1299.

8. (a) Smith, P. A. S. and Dounchis, H. J. Org. Chem. 38 (1973) 2958; (b) Smith, P. A. S., Breen, G. J. W., Hajek, M. K. and Awang, D. V. C. J. Org. Chem. 35 (1970) 2215; (c) Alcade, 
E., de Mendoza, J. and Elguero, J. J. Heterocycl. Chem. 11 (1974) 921.

9. (a) Smith, P. A. S., Krbechek, L. O. and Resemann, W. J. Am. Chem. Soc. 86 (1964) 2025; (b) Granados, R., Rull, M. and Villarasa, J. J. Heterocycl. Chem. 13 (1976) 281; (c) L'abbé, G., Vandendriessche, A. and Toppet, S. Tetrahedron 44 (1988) 3617 and references therein.

10. L'abbé, G. and Godts, F. Bull. Soc. Chim. Belg. 96 (1987) 229.

11. Gronowitz, S., Westerlund, C. and Hørnfeldt, A.-B. Acta Chem. Scand., Ser. B 29 (1975) 224.

12. (a) Lieb, F. and Eiler, K. Justus Liebigs Ann. Chem. 761 (1972) 130; (b) Vegh, D., Kovac, J. and Dandarova, M. Collect. Czech. Chem. Commun. 48 (1983) 1885; (c) Povazanek, F., Kovac, J. and Hesek, D. Collect. Czech. Chem. Commun. 45 (1980) 150.

13. Barnes, J. B., Newcombe, P. J. and Norris, R. K. Aust. J. Chem. 36 (1983) 963; Newcombe, P. J. and Norris, R. K. Tetrahedron Lett. 22 (1981) 699.

14. Noto, R., Arnone, C. and Rainieri, R. J. Chem. Soc., Perkin Trans. 2 (1989) 127

15. Boulton, A. J. and Middleton, D. J. Org. Chem. 39 (1974) 2956.

16. Spagnolo, P. and Zanirato, P. J. Org. Chem. 43 (1978) 3539.

17. Gronowitz, S., Spagnolo, P. and Zanirato, P. J. Org. Chem. 47 (1982) 3177.

18. Foresti, E., Spagnolo, P. and Zanirato, P. J. Chem. Soc., Perkin Trans. 1 (1989) 1354

19. Abramovitch, R. A. and Cue, W. B., Jr. J. Am. Chem. Soc. 98 (1976) 1478.

20. Abramovitch, R. A. and Cue, W. B., Jr. J. Org. Chem. 45 (1980) 5316.

21. Chippendale, K. E., Iddon, B. and Suschitzky, H. J. Chem. Soc., Perkin Trans. 1 (1972) 2023.

22. Spagnolo, P, Zanardi, G. and Zanirato, P. J. Chem. Soc., Perkin Trans. 1 (1983) 2551.

23. Chippendale, K. E., Iddon, B. and Suschitzky, H. J. Chem. Soc., Perkin Trans. 1 (1973) 125

24. Colburn, V. M., Iddon, B. and Suschitzky, H. J. Chem. Soc., Perkin Trans. 1 (1977) 2436.

25. Srinivasan, K., Srinivasan, K. G., Balasubramanian, K. K. and Swaminathan, S. Synthesis (1973) 313

26. Gronowitz, S., Westerlund, C. and Hørnfeldt, A.-B. Acta Chem. Scand., Ser. B 30 (1976) 391.

27. Farnier, M., Brost, M., Hanquet, B. and Guilard, R. Bull. Soc. Chim. France (1986) 513 and 517.

28. Moody, C. J., Rees, C. W. and Tsoi, S. C. J. Chem. Soc., Perkin Trans. 1 (1984) 915.

29. Gairns, R. S., Moody, C. J., Rees, C. W. and Tsoi, S. C. J. Chem. Soc., Perkin Trans. 1 (1986) 497.

30. Gairns, R. S., Moody, C. J. and Rees, C. W. J. Chem. Soc., Perkin Trans. 1 (1986) 501.
31. Gairns, R. S., Grant, R. D., Moody, C. J. and Rees, C. W. J. Chem. Soc., Perkin Trans. 1 (1986) 483.

32. Chippendale, K. E., Iddon, B. and Suschitzky, H. J. Chem. Soc., Perkin Trans. 1 (1973) 129.

33. Colburn, V. M., Iddon, B., Suschitzky, H. and Gallagher, P. T. J. Chem. Soc., Perkin Trans. 1 (1979) 1337.

34. Gronowitz, S., Westerlund, C. and Hørnfeldt, A.-B. Chem. Scr. 10 (1976) 165.

35. Gronowitz, S., Westerlund, C. and Hørnfeldt, A.-B. Chem. Scr. 12 (1977) 1.

36. Wright, J. B. J. Org. Chem. 34 (1969) 2475.

37. Kumar, G., Rajagopalan, K., Swaminathan, S. and Balasubramanian, K. K. Tetrahedron Lett. 20 (1979) 4685.

38. Choi, P., Rees, C. W. and Smith, E. H. Tetrahedron Lett. 23 (1982) 121.

39. Hassner, A. Vinyl Azides and Nitrenes. In: Scriven, E. F. V., Ed., Azides and Nitrenes-Reactivity and Utility, Academic Press, New York 1984, Chap. 2

40. L'abbé, G. and Beenaerts, L. Tetrahedron 45 (1989) 749.

41. L'abbé, G., Deketele, M. and Dekerk, J.-P. Tetrahedron Lett. 23 (1982) 1103; L'abbé, G., Deketele, M., Vanderstede, E. and Toppet, S. Bull. Soc. Chim. Belg. 97 (1988) 163.

42. (a) Becher, J., Brondum, K., Krake, N., Pluta, K., Simonsen, O., Molina, P. and Begtrup, M. J. Chem. Soc., Chem. Commun. (1988) 541; (b) Dehaen, W. and Becher, J. Tetrahedron Lett. 32 (1991) 3565.

43. Birch, D. J., Guildford, A. J., Tometzki, M. A. and Turner, R. W. J. Org. Chem. 47 (1982) 3547; Teulade, J. C.., Escale, R., Viols, H., Chapat, J. P., Grassy, G., Carpy, A. and Leger, J. M. J. Chem. Soc., Perkin Trans. 1 (1983) 2663.

44. Joucla, M. F. and Rees, C. W. J. Chem. Soc., Chem. Commun. (1984) 374.

45. Confalone, P. N. and Woodward, R. B. J. Am. Chem. Soc. 105 (1983) 902.

46. Irwin, W. J. and Wibberley, D. G. J. Chem. Soc. C (1971) 3238.

47. (a) Pluta, K., Andersen, K. V., Jensen, F. and Becher, J. J. Chem. Soc. Chem. Commun. (1988) 1583; (b) Garcia, J., Greenhouse, R., Muchowski, J. M. and Ruiz, J. A. Tetrahedron Lett. 26 (1985) 1827.

48. Burger, K., Geith, K. and Høss, E. Synthesis (1990) 352.

49. Spagnolo, P. and Zanirato, P. J. Chem. Soc., Chem. Commun. (1985) 1441.

50. Spagnolo, P. and Zanirato, P. J. Chem. Soc., Perkin Trans. 1 (1988) 3375.

51. Funicello, M., Spagnolo, P. and Zanirato, P. J. Chem. Soc., Perkin Trans. 1 (1990) 2971.

52. Toselli, M., Spagnolo, P. and Zanirato, P. Gazz. Chim. Ital. 119 (1989) 411

Received March 9, 1992. 